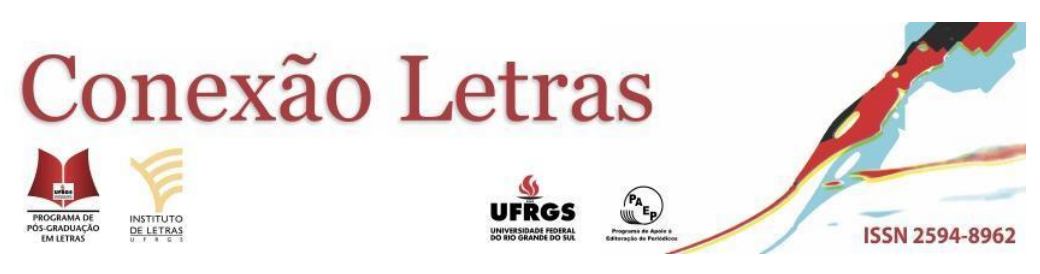

\title{
AGENCIAMENTO ENUNCIATIVO, REDES ENUNCIATIVAS: O CINISMO NA MOBILIDADE DOS SENTIDOS DA PALAVRA "NEGRA"
}

\author{
ENUNCIATIVE AGENCY, ENUNCIATIVE NETWORKS:THE CYNISM IN THE MOBILITY \\ OF THE MEANINGS OF THE EXPRESSION "BLACK WOMAN”
}

\author{
Soeli Maria Schreiber da Silva ${ }^{1}$ \\ Carolina de Paula Machado
}

\begin{abstract}
Resumo: Nosso objetivo é explicar a mobilidade do sentido de negra numa postagem do presidente da Fundação Cultural Palmares (FCP). Analisamos o agenciamento enunciativo (GUIMARÃES, 2002; 2018) e as redes enunciativas (DIAS, 2018). Por esta relação teórica, observamos que o funcionamento dos lugares enunciativos nos mostra diferentes movimentos na enunciação. Estes por sua vez se explicam no memorável e se ancoram nos referenciais históricos das redes enunciativas, aliados às enunciações estudadas. Vimos que ao significar negra, o referencial histórico ao qual se vincula o que é ser negro para o partido em questão é apagado para desmoralizá-lo e, por consequência, desmoraliza o movimento negro, produzindo uma enunciação com um efeito de cinismo.
\end{abstract}

Palavras-chave: Agenciamento enunciativo. Redes enunciativas. Negra(o). Referencial histórico. Pertinência enunciativa.

\begin{abstract}
Our goal is to explain the mobility of the sense of "black" in a post by the president of Fundação Cultural Palmares. We analyze the enunciative agency (GUIMARÃES, 2002; 2018) and the enunciative networks (DIAS, 2018). Through this theoretical relationship we observed that the functioning of the enunciative places show us different movements in the enunciation. These movements in turn are explained in the memorable and are anchored in the historical references of the enunciative networks allied to the enunciations were studied. This historical references are allied to the studied enunciations. We saw that by meaning "black woman", the historical reference linked to what it is to be black for the political party in question is erased. As a result the political party is demoralized and, consequently, demoralizes the black movement, producing an enunciation with an effect of cynicism.
\end{abstract}

Keywords: Enunciative agency. Enunciative networks. Black. Historical referential. Enunciative pertinence.

\section{Introdução ${ }^{3}$}

Quando estudamos a linguagem observamos que enunciar produz os sentidos que não são neutros e que se fazem com a história e o presente da enunciação. Este é o terreno em que atua a Semântica da Enunciação e, mais especificamente, a teoria da Semântica do Acontecimento. Nosso objetivo é explicar o que significa negra como um sentido atribuído a

\footnotetext{
1 É professora titular do Departamento de Letras da Universidade Federal de São Carlos (UFSCar). E-mail:xoila@terra.com.br.

2 É professora do Departamento de Letras da Universidade Federal de São Carlos (UFSCar) e professora do Programa de Pós-Graduação em Linguística (PPGL) também na UFSCar. E-mail: carolinapmac@gmail.com

${ }^{3}$ Agradecemos ao prof. Luiz Francisco Dias por suas conversas esclarecedoras.
} 
uma personalidade marcante no ano de 2020, a vice-presidenta dos Estados Unidos, Kamala Harris.

Parece simples definir o adjetivo negro/a, mas é uma palavra de grande importância política uma vez que aquilo que ela significa é motivo de debates. Quando a tomamos no acontecimento enunciativo, deparamo-nos com uma complexidade de filiações histórico-político-sociais para seus sentidos, emaranhados em disputas políticas. No Brasil, nos Estados Unidos, nos movimentos negros, dependendo do lugar de quem enuncia, ser negro(a) é significado diferentemente.

Faremos um pequeno recorte para analisar o acontecimento de um tuíte que se tornou notícia e os comentários dos leitores da notícia. Vamos tocar apenas em uma pontinha desse debate semântico em que se constitui uma história de sentidos da palavra "negra" ao analisar a notícia e os comentários como simbólicos da discussão sobre Kamala Harris, atual vice presidenta dos Estados Unidos, ser ou não negra e como essa questão é trazida na fala de Sérgio Camargo, um brasileiro, presidente da Fundação Cultural Palmares (FCP), sendo atualizada no acontecimento enunciativo de sua fala, imprimindo-lhe outras possíveis interpretações.

Buscaremos analisar os sentidos dessa palavra a partir das articulações que ela adquire com outras palavras e enunciados. Assim, vamos tentar compreender a pertinência enunciativa do predicativo atribuído à Kamala Harris, na sua enunciação por uma personalidade brasileira que ocupa um cargo de extrema relevância para os negros brasileiros, o de presidente da Fundação Cultural Palmares (FCP), às vésperas das eleições municipais do Brasil e às vésperas dos resultados finais das eleições norte-americanas.

Para tanto, nos apoiaremos no conceito de agenciamento enunciativo (GUIMARÃES, 2002, 2018) e nos conceitos de redes enunciativas, referencial histórico e pertinência enunciativa (DIAS, 2018, 2020).

Vejamos a postagem do Twitter que foi publicada como uma notícia pelo site UOL, no dia 11 de novembro de 2020 e que é parte do que iremos analisar neste artigo. 
Figura $1^{4}$

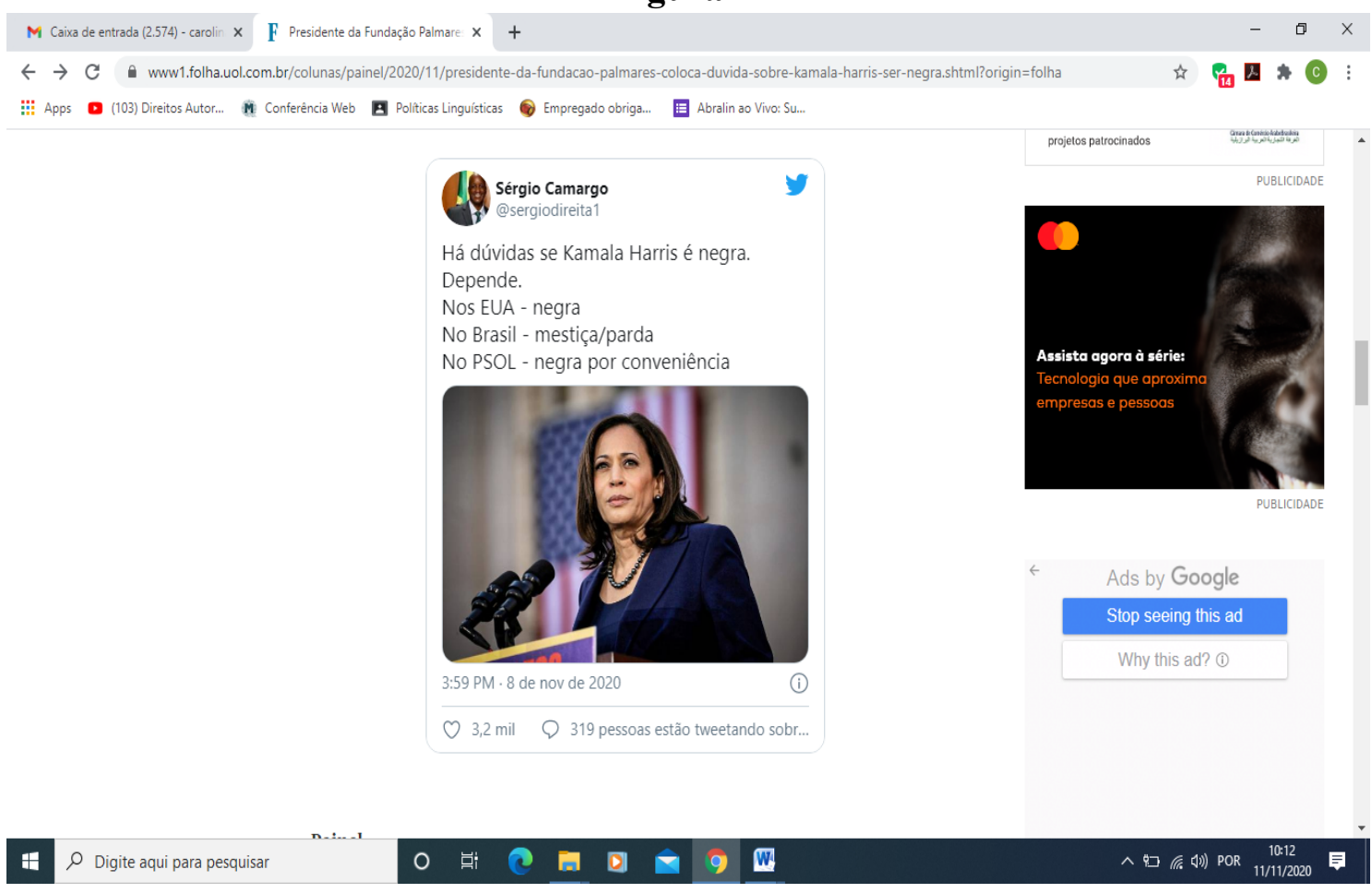

Vamos retomar de forma resumida uma análise feita anteriormente com algumas modificações $^{5}$, analisando nessa cena enunciativa o agenciamento enunciativo, e em seguida, faremos a análise das redes enunciativas do artigo jornalístico e dos comentários feitos sobre a notícia do tuíte em questão.

\section{Agenciamento Enunciativo do tuíte ${ }^{6}$}

Sérgio Camargo, autor da postagem acima, é presidente da Fundação Cultural Palmares (FCP), uma “instituição pública voltada para promoção e preservação dos valores culturais, históricos, sociais e econômicos decorrentes da influência negra na formação da sociedade brasileira (...)"

A postagem é de 08 de novembro de 2020, dias antes das eleições municipais do Brasil, e do Dia da Consciência Negra. Nos Estados Unidos, acontecia a apuração dos votos das eleições presidenciais norte-americanas, quando Joe Biden e, sua vice, Kamala Harris,

\footnotetext{
${ }^{4}$ Disponível em: https://www1.folha.uol.com.br/colunas/painel/2020/11/presidente-da-fundacao-palmares-coloca-duvida-sobre-ka mala-harris-ser-negra.shtml?origin=folha.

${ }^{5}$ Uma primeira versão desta análise da cena enunciativa foi apresentada no XXXV Encontro Nacional da Anpoll em 2020, com o título "O político e os sentidos: a produção das certezas na enunciação e seus efeitos em meio à pandemia", que será publicada nos anais do evento. Retomamos a análise com algumas modificações na descrição dos enunciadores.

${ }^{6}$ Tuíte ou Tweet é uma mensagem postada na rede social Twitter.

${ }^{7}$ Informações retiradas do site da instituição. Disponível em: Apresentação - Fundação Cultural Palmares. Acesso em: 14 fev. 2021. 
candidatos democratas, já despontavam como favoritos nas eleições, prenunciando a derrota do então presidente republicano Donald Trump.

A postagem traz a enunciação de uma dúvida e a resposta a ela. Vejamos:

"Há dúvidas se Kamala Harris é negra

Depende.

Nos EUA - negra.

No Brasil- mestiça/parda.

No PSOL- negra por conveniência."

Sérgio Camargo enuncia a dúvida e ele próprio a responde, o que contraria de certa maneira o que se espera em uma comunicação, significando-se como unidade do dizer, responsável por ele. Mas o curioso é que, apesar disso, ele não enuncia em primeira pessoa.

Então, para compreender os sentidos produzidos na enunciação dessa mensagem, a tomamos como um acontecimento enunciativo e, assim, saímos do conteúdo e deixamos de ver o autor empiricamente como falante que, nesse caso, falaria "a si mesmo" para olhar a “disparidade própria da divisão do falante” (GUIMARÃES, 2018).

Analisar o pequeno texto como um acontecimento enunciativo permite-nos, portanto, sair da evidência do conteúdo e apreender os sentidos produzidos na enunciação. A Enunciação é compreendida por Guimarães (2018) como um "acontecimento de linguagem" pois ao se dizer, algo ocorre. Ainda, segundo o autor, analisando um enunciado, considera que "a enunciação pode ser vista como o acontecimento em que o texto em que está enunciado se dá pelo funcionamento da língua, segundo suas sistematicidades próprias" (GUIMARÃES, 2018, p. 21). Sendo, portanto, a enunciação "um acontecimento que produz sentido" (GUIMARÃES, 2018, p. 22).

Ele então retoma sua definição de acontecimento como sendo "o que faz diferença na sua própria ordem" (GUIMARÃES, 2018, p. 37). Assim, o acontecimento se organiza em uma "temporalidade de sentidos" própria - presente, passado (memorável) e futuro (futuridade).

$\mathrm{Na}$ medida em que produz sentidos pela língua em funcionamento, "o acontecimento agencia o falante a dizer enquanto um lugar de enunciação, como lugar que enuncia" (GUIMARÃES, 2018, p. 41). Então não se trata de analisar o sentido que ele 'quis' ou teve a ‘intenção' de produzir, mas os sentidos que se constituem na enunciação em função do 
agenciamento enunciativo do falante, produzido pelo acontecimento do funcionamento da língua.

Esse agenciamento constitui a alocução por agenciar o falante em "em aquele que diz algo para alguém", lembrando-se que não estamos olhando para pessoas empíricas mas figuras enunciativas agenciadas sócio historicamente. O modo de dizer as formas linguísticas constituem o dizer como um dizer de uma figura enunciativa para outra, uma projeção. Assim, eles são chamados de Locutor (o lugar que diz, responsável pelo dizer e pela unidade do texto) e Locutário (o lugar para quem se diz).

A questão é que quando falamos, falamos agenciados por um lugar de dizer, a partir de certos lugares sociais, ou seja, o que dizemos não é neutro. Assim é que o que se diz é dito de um lugar social do dizer, e desse modo, Guimarães considera que há uma divisão do Locutor que enuncia como alocutor-x (al-x), sendo a variável o lugar social de quem enuncia constituído pelo agenciamento enunciativo. $\mathrm{O}$ agenciamento do Locutor por um ou mais lugares sociais também produz o agenciamento para a figura do Locutário que será chamado de alocutário-x (at-x).

$\mathrm{O}$ agenciamento dos falantes a dizer configura a cena enunciativa. A especificidade deste conceito é que isto se dá pela divisão desigual dos lugares de enunciação, o que o caracteriza como político ${ }^{8}$.

Assim, para o autor,

A cena enunciativa se constitui pelo agenciamento do falante a dizer. O agenciamento do falante o divide na cena em lugares de enunciação: o daquele que diz (Locutor), o lugar social de dizer (alocutor), e o lugar de dizer (enunciador). Esta divisão dos lugares de enunciação constitui o que chamamos aqui de politopia da cena enunciativa. (GUIMARÃES, 2018, p.71-72)

Nesta divisão de lugares de enunciação em conflito que Guimarães chama de politopia, ainda tem a figura do enunciador. Esta figura enunciativa consiste nas diferentes maneiras de apresentar o que se diz. Pode-se apresentar o que é dito como algo que é dito por uma coletividade, de forma impessoal, é um lugar de dizer coletivo, o enunciador coletivo. Por outro lado, o Locutor pode dizer de forma individual, apresentando o que diz como um dizer próprio, que se representa como se não falasse de um lugar social, como se fosse uma enunciação que se dá independentemente da história. É o enunciador individual que se representa como um lugar que está acima dos demais.

\footnotetext{
${ }^{8}$ O político "se caracteriza pela oposição entre uma afirmação da igualdade em conflito com uma divisão desigual do real produzida enunciativamente pelas instituições que o organizam: organizam os lugares sociais e suas relações, identificando-os (ou seja, atribuindo-lhes sentido), e recortam as coisas do mundo significando-as. Por este conflito, o real se divide, redivide, se refaz incessantemente em nome do pertencimento do todos no todos." (GUIMARÃES, 2018, p. 50). 
Quando o que se diz é dito como uma verdade por uma relação com os fatos e, desse modo, também seria independente do social e do histórico, o enunciador é universal.

Por fim, o enunciador genérico apresenta o que diz como um "dizer difuso, indeterminado, sem que se possa considerar sua validade para todos" (GUIMARÃES, 2018, p. 67). Ainda, este locutor representa o seu dizer como um dizer próprio, ele "simula ser a origem do que aqui se diz. Mas o que aí se diz é dito como aquilo que todos dizem" (GUIMARÃES, 2002, p. 25).

Voltemos então à nossa análise. A dúvida enunciada não é dita de modo individual, isto é, não é propriamente de Sérgio Camargo, Locutor do texto, que prontamente a responde, sendo assim ele próprio o Locutário. Isso já nos dá indícios de que a enunciação não tem como efeito dar a conhecer a seus leitores/seguidores no Twitter, os alocutores que possivelmente compartilham a dúvida enunciada, que ele está em dúvida sobre isso, e, muito menos que a enunciação da dúvida seja um ato perlocucionário, ${ }^{9}$ que teria como consequência que seus alocutários respondessem à dúvida, pois ele próprio já dá a resposta. Nesse sentido, como analisar a performatividade da dúvida? Então, o que se produz como sentidos ao se enunciar esta dúvida?

$\mathrm{Na}$ análise que ora retomamos, vimos que o agenciamento do Locutor pelas condições sócio-históricas, dá-se pelo nome próprio "Sérgio Camargo", que sabemos ser o presidente da Fundação Cultural Palmares (FCP), e pela identificação digital @sergiodireital. Ou seja, constitui-se o lugar social de presidente da FCP, e da posição política de direita, posição conservadora, filiada a uma visão política neoliberal.

De um lugar de dizer genérico, enuncia “Há dúvidas se Kamala Harris é negra”, em que ao mesmo tempo em que simula ser a origem do que diz, isto é dito como algo que todos dizem, como um dizer difuso e indeterminado, como se fosse uma dúvida compartilhada por todos, perspectiva apresentada pelo alocutor-presidente da FCP. "O enunciador se mostra dizendo com todos os outros: se mostra como um indivíduo que escolhe falar como os outros indivíduos, uma forma de se apresentar como independente da história" (GUIMARÃES, 2002, p. 25). Estes modos de dizer se fazem como se o locutor não falasse agenciado por lugares sociais.

\footnotetext{
${ }^{9}$ Não analisamos o enunciado a partir da visão de Austin da performatividade do dizer, em que "dizer é fazer". Do ponto de vista do autor, poder-se-ia dizer que o locutor ao enunciar a dúvida teria como intenção ou objetivo produzir como um ato perlocucionário, isto é, como consequência a resposta a esta dúvida (AUSTIN, 1990). Mas como vemos, o próprio locutor do texto responde à dúvida. A partir de Austin, trataríamos a dúvida como um ato performativo.
} 
Essa perspectiva se opõe a outra que fica implícita, que pode ser formulada por um enunciado como "Kamala Harris é negra", dita por um enunciador universal, como algo que seria isento de qualquer contestação, isto é, como uma certeza por ser tomada como verdade. No entanto, esta certeza é contestada na enunciação do alocutor-presidente da FCP, dúvida apresentada no ato performativo de dúvida com o enunciado "Há dúvidas se Kamala Harris é negra".

Em seguida, vem a resposta relativizada em função do país/partido o que justificaria a dúvida. Vejamos:

Depende.

Nos EUA - negra.

No Brasil- mestiça/parda.

No PSOL- negra por conveniência.

Para uma melhor descrição da análise, podemos parafrasear os três últimos enunciados por:

\section{Kamala Harris é negra nos EUA. \\ 2. Kamala Harris é mestiça/parda no Brasil. \\ 3. Kamala Harris é negra por conveniência no PSOL.}

Pela resposta, temos que o que significa o adjetivo negra/negro em convergência ao nome próprio Kamala Harris não é o mesmo para todas as pessoas.

No enunciado 1, o Locutor enuncia que Kamala é negra como algo que é verdadeiro nos Estados Unidos, independentemente de qualquer discordância e de seu próprio lugar social, acima da história e do social. O Locutor enuncia, portanto, como enunciador universal.

\section{L (E. universal)- Kamala Harris é negra nos EUA.}

O mesmo acontece no enunciado 2, em que o Locutor enuncia como enunciador universal, isto é, como uma verdade que, no Brasil, Kamala seja considerada mestiça ou parda. Ou seja, essas enunciações se representam como verdades em cada um desses países, como se dizer negra ou mestiça fosse um mero reconhecimento da cor e não tivesse nada a ver 
com a história de colonização e de escravização de cada país e muito menos com as reivindicações antirracistas e de igualdade de direitos dos movimentos negros.

\section{L (E. universal) - Kamala Harris é mestiça/parda no Brasil.}

No entanto, apesar da articulação dos predicados feita com distintos países se apresentar como algo evidente, como uma mera localização geográfica, essa localização recorta memoráveis ${ }^{10}$. Sem levar isso em consideração na leitura dos enunciados, dizer $e ́$ negra, é mestiça ou é parda se realizam como enunciações banais, como se a diferença de sentidos entre dizer negra, mestiça/parda dependesse apenas de em que país estamos para nomear a cor da pele.

Enquanto nos dois primeiros enunciados a localização por país justificaria a diferença em designar Kamala pelo sentido de negra ou de mestiça/parda, no último enunciado temos uma mudança. A determinação do sentido de "negra(o)" muda da categoria de país para a de partido político.

No último enunciado-resposta, a palavra negra está articulada a por conveniência, que a determina semanticamente com o sentido de ser uma característica que se altera para ser favorecido, de modo oportunista. Neste enunciado, temos uma divisão do Locutor. Há um enunciador universal que diz que no PSOL, Kamala Harris é negra, mas há outro enunciador que considera que dizer que Kamala Harris é negra no PSOL é por conveniência, um dizer que é de um lugar individual, que estaria acima dos demais lugares. Vejamos então a descrição desta divisão de lugares enunciativos através das paráfrases:

L (E.Universal): No PSOL, Kamala Harris é negra.

$L$ (E. Individual): Eu afirmo que é por conveniência que no PSOL Kamala Harris é negra.

Como dissemos anteriormente, apesar da figura enunciativa do enunciador se colocar como fora ou independente da história e do social, o Locutor é agenciado pelo dizer como alocutor-presidente da FCP, e se nomeia como "de direita" como já vimos. Assim, nessa

\footnotetext{
${ }^{10} \mathrm{O}$ memorável é uma memória relativa à temporalidade constituída no acontecimento do dizer. Trata-se de uma rememoração de enunciações que é parte de uma nova temporalização e projeta sentidos(futuridade). (GUIMARÃES, 2002). Trata-se dos sentidos de enunciações passadas no presente do dizer que projeta sentidos futuros (GUIMARÃES, 2018). 
divisão de lugares, o alocutor-presidente da FCP, de direita, alude ${ }^{11}$ o Locutor, o responsável pelo dizer, sustentando assim seu argumento de que é por conveniência que Kamala Harris é considerada negra no PSOL.

Observamos que do lugar social dos norte-americanos, Kamala pode ser considerada negra. Já o PSOL, Partido Socialismo e Liberdade, não teria a mesma legitimidade em dizer "é negra" para Kamala, mesmo que faça parte de seu programa de partido a luta contra o racismo e a luta pelos direitos dos negros, sendo forte o movimento negro dentro dele. Assim,

Vemos, pelo funcionamento do político no agenciamento dos falantes, a distribuição dos lugares entre aqueles que podem dizer "é negra' e aqueles que não podem, e a desconstrução do sentido de "negro(a)", como forma de enfraquecimento, de desmoralização da causa antirracista defendida pelo partido e do próprio partido. (MACHADO, 2020).

Acrescentamos ainda que esta distribuição desigual de quem pode qualificar Kamala como negra ou mestiça/parda ou negra por conveniência dá-se do lugar social do alocutor agenciado do lugar de presidente da FCP, de direita, que enuncia ora de modo universal, ou seja, Kamala ser negra como algo verdadeiro nos EUA, ser mestiça ou parda no Brasil, também como algo verdadeiro. E de modo universal e individual em que afirma que no PSOL ela seria negra (E. Universal), mas para ele (E. Individual) considerar Kamala como negra pelo PSOL é por conveniência.

Analisando os sentidos dos enunciados como integrantes do sentido do texto, o sentido projetado como futuridade da enunciação do enunciado "No Brasil, é mestiça ou parda" como uma verdade seria o de que "No Brasil, Kamala Harris não é negra". Isto sustenta a conclusão a que os alocutários-leitores são levados: "Se o PSOL afirma que ela é negra, ele o faz por que lhe é conveniente, em função de seus interesses partidários." Desconsidera-se a questão de "negro" poder ter não apenas o sentido de "cor da pele" como algo neutro, mas ter seus sentidos determinados pelo histórico, político e ideológico tal como é abordado na política de cotas, ou como foi abordado na ideologia do branqueamento, etc.

Até o momento, analisamos a dinâmica da cena enunciativa, isto é, a divisão do Locutor e a distribuição do dizer. Nos enunciados de Sérgio Camargo, podemos observar a disparidade do dizer na medida em que ele, agenciado sócio historicamente, se movimenta entre o lugar social de dizer, de presidente e o lugar político de direita e enquanto pessoa

\footnotetext{
${ }^{11}$ Para Guimarães, "a alusão, no sentido que dou a este termo aqui, é uma relação de um lugar de enunciação que evoca um outro lugar de enunciação e o que se diz a partir deste lugar. (GUIMARÃES, 2018, p. 69) 
(Locutor), sob o efeito de universalidade, o efeito de indeterminado, de modo a simular que muitas outras pessoas pensam dessa forma.

Enquanto o Locutor orienta seu discurso para o apagamento da história sob um sentido único para "negra", na análise do agenciamento enunciativo observamos esse funcionamento quando, pela disparidade do Locutor, vemos que há uma divisão de lugares na enunciação determinada sócio historicamente pelo lugar social do Locutor e pelos lugares do dizer, de forma que "negra" tem outros sentidos e não apenas o que se apresenta na evidência dos enunciados ditos por ele.

Para melhor compreendermos o significado de "negra" na convergência para Kamala Harris vamos passar a análise da significação com os conceitos de Referencial Histórico, Pertinência Enunciativa e Redes Enunciativas (DIAS, 2018).

\section{Referencial Histórico": O(a) "negro(a)" e o racismo}

A palavra "Negro(a)" tem vários significados sendo muito difícil apreender seus diferentes sentidos ${ }^{13}$. Como vemos, essa palavra também não tem o mesmo significado no Brasil e nos Estados Unidos, como está patente no recorte analisado. Isto está atrelado ao modo específico de como a escravidão aconteceu em cada um desses países e de como a miscigenação foi tratada em cada sociedade.

Para Hofbauer (2006) a diversidade de sentidos do termo 'negro' está relacionada à 'história deste conceito' ligada ao desenvolvimento de 'teorias raciais' empregadas para explicar as diferenças entre os seres humanos. Ele alerta para o fato de que os conceitos das teorias são usados como "dados objetivos da realidade", como conceitos que reportam ao que é natural, e não como "partes integrantes de discursos específicos sobre o mundo empírico" (HOFBAUER, 2006, p. 18). Ainda, segundo o autor, “(...) é preciso ligar as abordagens sobre a "diferenciação de cor de pele" à fundamentação teórico-ideológica dos diferentes discursos de inclusão e exclusão de cada época.” (HOFBAUER, 2006, p. 18)

\footnotetext{
${ }^{12} \mathrm{O}$ conceito de referencial histórico será desenvolvido com mais detalhes na próxima seção.

${ }^{13}$ Para termos ideia da complexidade, Hofbauer (2006) nos diz que "a palavra "negro" vem sendo usada - muitas vezes num único discurso- com conteúdos semânticos bastante diferentes: ora refere-se à cor da pele, ora a uma "manifestação cultural" herdada do mundo africano, ora a um "jeito de ser", de mexer-se, ora ainda a um estilo musical, e assim por diante". (HOFBAUER, 2006, p. 14). Ele mesmo propõe tentar compreender os 'descompassos' entre o 'negro político' dos movimentos negros de resistência, e o 'negro cultural-religioso' das religiões africanas como o candomblé, já que não recobrem como ele coloca em questão quando pergunta pelo significado do adjetivo "negro".
} 
Para ele, então, na história do racismo brasileiro, o branqueamento é um conceito de fundamental importância. Difundiu-se a teoria do branqueamento ou, como tem sido chamada na literatura, a "ideologia do branqueamento" (HOFBAUER, 2006).

A tese do branqueamento é essencialmente desenvolvida por intelectuais brasileiros, no final do século XIX e início do século XX. O racismo científico europeu acreditava que a mistura de raças produzia a regressão da raça branca. Esta se diluiria quando misturada a pessoas de raças não brancas. Intelectuais brasileiros, como Oliveira Vianna e João Batista Lacerda, discordaram desta ideia e afirmavam que eram os atributos raciais brancos que dominavam quando havia mistura de raças. Desse modo, no caso do Brasil, as características raciais africanas e indígenas seriam eliminadas com a mistura com os imigrantes europeus, que no início do século XX passam a vir trabalhar no Brasil incentivados pela política da época.

Esse discurso científico e político teria sido específico ao Brasil para solucionar seus problemas sociais e políticos pós-abolição e não teria sido empregado na Europa e nos Estados Unidos, conforme Skidmore (1989) apud Hofbauer (2006). Ainda, segundo o autor, o ideal do branqueamento tornou-se "o coração do ideal racial brasileiro".

Como vemos, no Brasil, a miscigenação foi tratada como algo que eliminaria os traços africanos e indígenas, vistos como negativos, e assim levaria ao branqueamento. Ao contrário, nos Estados Unidos, o racismo colocou de outro modo pois acreditava-se, pelas teorias raciais, que a miscigenação produziria a regressão das características da raça europeia branca. Neste país, há a regra "se tem uma gota de sangue é negro/a", no inglês "One drop rule", em que independentemente tonalidade da pele, Kamala é considerada negra. Esta regra foi elaborada nos Estados Unidos, no início do século XX para impedir o casamento entre negros e brancos e, com isso, a mistura de raças.

Assim, a identificação como mestiço(a), pardo(a), etc, no Brasil, longe de se limitar a uma questão de cor simplesmente, como algo natural, estaria ancorada nesse discurso científico do branqueamento, tão forte no Brasil, que leva muitas pessoas a não se identificarem como "negras".

Por outro lado, nos Estados Unidos, que não aceitou esta ideia do branqueamento acreditando na ideia da regressão das raças, condenava a miscigenação. Assim, vemos que a identificação de dá como "negro" ou "branco" de forma absoluta.

Hofbauer (2006), comentando Roberto DaMatta (1997), diz que “O antropólogo chama a atenção para o fato de que, diferentemente do "sistema racial" bipolar dos Estados 
Unidos que define mestiço como negro, no Brasil, as relações sociais são dominadas por "uma ideologia de mistura e ambiguidade", que faz com que o mestiço simbolize “integração”(HOFBAUER, 2006, p. 24).

No âmbito dos movimentos negros, identificar-se como "negro", "pardo", "mestiço" tem a ver com a história da escravidão e todo o prejuízo que os africanos e seus descendentes sofreram e com suas características e cultura historicamente construídas de forma pejorativa como forma de dominação e imposição da cultura do colonizador, para com isso redefini-las positivamente.

Nos países em que houve escravidão dos africanos, a escravidão deixou um legado de pobreza, desigualdade e racismo para os afrodescendentes. Os movimentos negros lutam pelos direitos dos negros, pela igualdade racial, contra o racismo. Uma das questões que perpassa essa luta é a de busca em se mudar a visão pejorativa das características do povo negro reconstruindo positivamente sua identidade pela valorização se suas características, não apenas das características físicas, mas de sua cultura e história, por isso, ser negro tem uma importância enorme como forma de resgatar a identidade dos afrodescendentes.

O combate ao racismo e à opressão dos negros é uma das questões principais do programa do Partido Socialismo e Liberdade (PSOL), de esquerda, incluindo, portanto, a luta/resistência do movimento negro entre suas causas. Nesta visão, "negro(a)" diz respeito à identidade negra a qual se busca (re)construir. E isso vai além de uma questão de estética, tem a ver com a reorganização da cultura afro-descendente que foi diluída e ou criminalizada. Para Jocelício Júnior, presidente do PSOL, “a identidade negra vai além da disputa estética de autoafirmação e busca por visibilidades, ela está associada a uma estratégia de organização social contra-hegemônica." (JÚNIOR, 2018) $)^{14}$

Como forma de reparação histórica, existem políticas de ações afirmativas, sendo a política de cotas uma delas, como formas de aumentar a representatividade de pessoas de origem negra e de indígena. As cotas são a reserva de vagas para aquele(a)s que têm origem negra e para indígenas. Pessoas com necessidades especiais também estão incluídas na reserva de cotas. Elas valem não apenas para o ingresso daquele(a)s que se autodeclaram negros nas universidades públicas como para seu ingresso em concursos públicos. A instituição das cotas raciais e sociais, aconteceu com a lei 12.990 criada em 2012.

\footnotetext{
14 Artigo intitulado "PSOL: Abrigo da resistência Negra". Disponível em: https://psol50.org.br/joselicio-junior-psol-um-abrigo-da-resistencia-negra/ Acesso em: março de 2021. 


\title{
Referencial Histórico, Pertinência Enunciativa, Redes Enunciativas e Perspectivação: a convergência de negra na relação com o nome próprio Kamala Harris.
}

Vamos explicitar concepções que estarão presentes no estudo que nos propomos fazer. Antes de tudo, trata-se de um modo de conceber a significação. Assim, interessa o já significado que o acionamento da língua evoca e o que se apresenta no presente da enunciação para significar. Desse modo, a enunciação significa o mundo presente pela memória das significações do mundo passado. Podemos dizer ainda que, nesse sentido, as relações entre o que já faz sentido em referenciais históricos e um fazer sentido tendo em vista as pertinências enunciativas, que o enunciado apresenta no presente da enunciação, vão especificar a enunciação. Então apresentamos o conceito de referencial histórico:

\begin{abstract}
o conceito de referencial tem raiz nesse suporte institucional dos nossos dizeres, isto é, na filiação que eles adquirem tendo em vista o funcionamento histórico da sociedade, especificamente o complexo de regulações, admissões, proibições, incentivos. $\mathrm{O}$ referencial constitui-se, portanto, em um dos dois fundamentos daquilo que designamos por razão enunciativa das relações linguísticas. Trata-se dos domínios em que os enunciados se ancoram para se situarem segundo o funcionamento histórico social. (DIAS, 2018, p. 101)
\end{abstract}

O fazer sentido no enunciado precisa levar em conta as relações de pertencimento do enunciado a uma atualidade do dizer, ancorada ou sustentada em domínios referenciais históricos. Aí vamos buscar a pertinência do enunciado, os motivos ou razões para relações entre unidades linguísticas, isto é, analisamos como as formas se agregam umas às outras. "Uma forma linguística constitui-se como tal na conformação de unidades às regularidades da língua, tendo em vista o seu acionamento enunciativo" (DIAS, 2018, p. 37). Também podemos dizer que "ao enunciar direcionamos e mobilizamos formas no sentido de qualificá-las na enunciação" (DIAS, 2018, p. 42).

Dias (2018, p. 103) nos fala que "o dizer produz um compromisso de aderência com outros dizeres em um campo de enunciação”. Para nós, não se trata simplesmente de tomar o passado para trazê-lo ao presente, mas de formular o presente na relação com o passado aderindo-o e dando outra direção para o presente. Esse é o compromisso de aderência.

Na sequência, vejamos o conceito de pertinência enunciativa que se constitui como o outro conceito para análise das razões enunciativas. Esse conceito

se fundamenta à ideia de adesão. Enquanto seres de linguagem, vale dizer enquanto seres constitutivamente históricos, nós somos instados a responder, a interpretar, a interferir enunciativamente nas situações que se nos apresentam. É a 'demanda do presente' que estamos denominando 'pertinência enunciativa'. As respostas, as interpretações, as interferências que se efetivam na enunciação, isto é, as respostas às demandas do presente são constitutivas do acontecimento enunciativo. (DIAS, 2018, p. 103) 
As diferentes demandas do presente são de diferentes ordens e sempre nos afetam. Somos instados a dizer, a fazer sentido na linguagem, a nos fazer reconhecidos pela linguagem, a intervirmos no mundo em que vivemos.

Assim, no nosso estudo

\begin{abstract}
observar a enunciação envolve conceber as dinâmicas de dimensões de sentido, por meio da qualificação das formas de expressão (formas significantes) como passíveis de receber a determinação de domínios de mobilidade capazes de qualificá-las enunciativamente. (DIAS, 2019, p.31)
\end{abstract}

Vimos na análise da cena enunciativa que na perspectiva de Guimarães (2018) a significação dos enunciados do Presidente da Fundação Palmares é auferida pela politopia, ou seja, "o locutor só pode dizer enquanto Al-x na medida em que na alocução divide a cena da enunciação com o Alocutor" (GUIMARÃES, 2018, p.73). Assim, temos que Kamala é designada como negra nos Estados Unidos, como mestiça/parda no Brasil, como negra por conveniência no PSOL, diferentes formas de designar que se dão de lugares enunciativos diferentes. Como efeito da universalidade do dizer, é como se a história do racismo não existisse e como se não fosse diferente entre os países, e como se não houvesse motivos históricos e sociais para se considerar Kamala Harris negra. Aí entra então o enunciador individual, respaldado pelo lugar de social de Presidente da Fundação Cultural Palmares e da posição política "de direita", que afirma que ela é negra por conveniência no PSOL.

Agora vamos tratar do mesmo recorte na perspectiva de Dias (2018) para vermos o que esses adjetivos significam na convergência com o nome Kamala Harris, mostrando que o adjetivo negra não tem o mesmo sentido nos enunciados em questão. Observaremos também os comentários feitos à notícia em que o tuíte foi trazido. Para isso, três conceitos são fundamentais: o primeiro é referencial histórico; o segundo é a pertinência enunciativa, e o terceiro é o conceito de rede enunciativa.

Em primeiro lugar precisamos considerar que "os papéis que nos identificam na sociedade (...) os nossos dizeres sofrem determinações sobre o que dizer, o que não dizer, como dizer" (DIAS, 2018, p. 97). A esses dizeres identificados na sociedade, dizemos que são dizeres sociais e esses dizeres "se apoiam em um suporte institucional" (DIAS, 2018, p. 97).

$\mathrm{Na}$ perspectiva de "negra" na convergência com o nome Kamala Harris que vamos analisar, poderemos ver que

O compromisso de um nome não é com a entidade em si, mesmo porque ele não existiria nessa condição, mas com o campo de emergência de entidades recortado da exterioridade. Trata-se de um recorte enunciativo, porque essas entidades não se encontram discriminadas e delimitadas na natureza. A enunciação irá torná-las 
pertinentes aos acontecimentos em linguagem, tendo em vista as possibilidades históricas que as fazem emergir. (DIAS, 2018, p. 100).

Sérgio Camargo, como veremos, põe em dúvida a significação do referencial histórico em que se ancora predicar Kamala Harris como negra. Os domínios de mobilização de sentido em que seus enunciados se ancoram visam a negar ou a não admitir a negritude de Kamala Harris.

O segundo conceito é o de pertinência enunciativa. Diríamos que não há adesão ao referencial histórico de negra na convergência com Kamala Harris ao qual se ancora o primeiro enunciado; entre o dizer de Sérgio Camargo e o referencial histórico não há pertencimento; essa relação de pertencimento dá-se na relação com o referencial histórico, ancora-se nele. Isto que veremos nas análises. Não podemos deixar de dizer que enunciar não é somente trazer um passado para o presente; o passado se atualiza e daí temos a pertinência enunciativa. Para explicar o terceiro conceito, o de rede enunciativa, Dias (2018) trabalha e critica os exemplos isolados que a Escola efetua quando se trata de conhecimentos linguísticos, e aí propõe um trabalho com as redes enunciativas:

a constituição de uma rede enunciativa envolve a formação de contrastes entre a construção linguística em estudo e outras construções com estruturas semelhantes e palavras iguais, no sentido de permitir a percepção da mobilização que a enunciação sustenta. Essas construções outras trazidas para a rede enunciativa são construídas pelo próprio pesquisador e/ou também podem ser buscadas em usos efetivos (...) (DIAS, 2018, p. 35).

Esse conceito vai permitir que analisemos a mobilização na qual a enunciação se sustenta. $\mathrm{O}$ autor afirma que

utilizamos redes enunciativas para criar ambiente de observação das relações de sentido na linguagem por meio de articulações entre as unidades linguísticas (substantivo, verbo, advérbio). Enfim, a rede enunciativa é uma técnica de demonstração das relações de sentido de um enunciado (DIAS, 2020, p. 10).

Quando falamos em relações de sentido, vamos analisar o efeito de cada enunciado na relação com os referenciais históricos para projetarmos um sentido diferente do que está posto.

O conceito de perspectivação diz respeito à projeção que se dá a partir da pertinência enunciativa. Em Schreiber da Silva (2018), pode-se ver essa análise da perspectivação como argumentação.

A nossa pergunta nessa parte do nosso estudo é como "negra" é significada na convergência com Kamala Harris? Retomemos o recorte:

Há dúvidas se Kamalla Harris é negra. 
Depende.

Nos EUA - negra

No Brasil - mestiça/parda

No PSOL - negra por conveniência

No primeiro momento analisamos três redes enunciativas correspondentes aos três últimos enunciados do recorte. Nosso objetivo é determinar a significação do adjetivo na convergência com o nome Kamala Harris. O corpus envolve o texto de Sérgio Camargo integrado aos textos dos comentários feitos por internautas e à dúvida apresentada por Sérgio Camargo. Segue a rede enunciativa 1:

Kamala Harris é negra nos EUA.

(a') Kamala Harris é chamada negra $\operatorname{nos} \mathrm{EUA}^{15}$.

(b’) Seu nariz e lábios são finos e não é muito mais escura que de um português ou árabe. ${ }^{16}$

(c') Lá é ou branco ou negro. ${ }^{17}$

Nessa primeira rede enunciativa, em (a') negra se articula com nos para especificar o localizador; nesse funcionamento, a pertinência enunciativa dá-se na localização para determinar negra; em chamada temos um sentido em que negra é apelido. O ponto de vista ou referencial histórico em (a') tem a ver com o modo como se considera negra nos EUA, só havendo o adjetivo negra. Já em (b') o adjetivo finos determinando nariz e lábios nega a negritude de Kamala Harris; e a pele não é muito mais escura que de um português ou árabe também nega a negritude. Em (a') temos uma pertinência enunciativa que põe o localizador EUA e um nome não legitimado, na medida em que é apelido. Negra determina Kamala Harris pelo localizador e chamada determina negra como apelido. Kamala Harris é determinada como negra, sendo um apelido. Em (b') temos a característica do corpo e da pele. Em (c') "lá" é uma anáfora de EUA e ou branco ou negro determinam negra incluindo a

\footnotetext{
${ }^{15}$ Fragmento retirado do comentário de Paulo César Oliveira à notícia.

${ }^{16}$ Fragmento retirado do comentário de Paulo César Oliveira à notícia.

${ }^{17}$ Fragmento retirado do comentário de Maurício Ferrante.
} 
separação de raças. Esse referencial histórico evoca a separação branco ou preto, uma vez que nos EUA banheiros públicos e assentos de ônibus e escolas eram separados para negros e para brancos e, sobretudo, brancos e negros não podiam casar entre si. Mesmo com os movimentos de adeptos da resistência, resta ainda uma separação pela cor identificada por negra ou por branca. Na relação com negro só há essa caracterização. Inclui somente duas raças na negritude por contraste a (b'). Assim o ou nos mostra que os brancos são incluídos entre os brancos e os negros entre os negros, sendo descendente, mais claro ou mestiço. A pertinência enunciativa orienta para a projeção de Kamala Harris negra, projetando uma cor de pele pela evidência de não ser branca, não pela separação de cores ou mestiçagem como é no Brasil, que se deu, inicialmente, pela ideologia do branqueamento. Em (c') não há outra alternativa além de branca e negra, pelo referencial histórico da segregação entre brancos e negros tal como se deu nos EUA; nesse referencial, a pertinência enunciativa é Kamala Harris determinada como negra. A perspectivação dá-se na contradição, uma vez que o enunciado (b’) evoca o referencial histórico de uma separação especificada pela mistura de raças.

A segunda rede enunciativa explicita a convergência do nome Kamala Harris com os adjetivos mestiça /parda:

Kamala Harris é mestiça/parda no Brasil. (a") Nos EUA não há mistura de raças

(são racistas, lembra?), portanto não há necessidade de quantificar matizes de cores. ${ }^{18}$

(b") No Brasil, mestiça e parda tem a ver com miscigenação ${ }^{19}$.

(c") No Brasil, mestiça, parda e descendência negra fazem parte das cotas. ${ }^{20}$

Nessa rede enunciativa, em (a"), nos EUA não há mistura de raças; a negação da mistura determina negra; observe-se que não ter mistura de raças e racistas do parênteses determinam Kamala Harris como negra. A conclusão é que nos EUA não há necessidade de

\footnotetext{
${ }^{18}$ Fragmento retirado do comentário de Maurício Ferrante.

${ }^{19}$ Enunciado elaborado por nós.

${ }^{20}$ Enunciado de elaboração própria. 
quantificar matizes de cores, determinando Kamala Harris como negra considerando o referencial histórico dos EUA.

Em (b"), temos o localizador no que determina Brasil; o referencial histórico é a mestiçagem, enquanto nos EUA branco não podia casar com negro e vice versa; nessa rede enunciativa tanto o localizador Brasil como Kamala Harris na convergência com mestiça e parda determinam o nome Kamala Harris como mestiça no Brasil pelo referencial histórico da mestiçagem. A pertinência enunciativa projeta a perspectivação Kamala Harris mestiça Iparda pela cor, pela mistura e pela descendência ; em (b") temos o localizador Brasil e a caraterização da cor e da mistura de raças; Brasil, mestiça e parda determinam Kamala Harris; em (c") além da divisão de cores e mistura mestiça/parda para determinar Kamala Harris, temos também a descendência; o referencial histórico tem a ver com as políticas afirmativas e o movimento pelas cotas; a pertinência enunciativa é a concepção de cor de pele no Brasil; mestiça determina Kamala Harris no enunciado. O referencial continua sendo a mistura de raças incluindo a descendência para determinar a cor; a pertinência enunciativa vai além da cor de pele porque inclui a descendência. Nessa segunda rede enunciativa, a pertinência enunciativa é a concepção de mistura na cor da pele e descendência como características de negra, na perspectivação de Kamala Harris mestiça e descendente de negros considerada negra pela política das cotas estabelecida pelo movimento negro no Brasil. Vejamos a terceira rede enunciativa, para explicitar a convergência de negra por conveniência:

Kamala Harris é

negra por conveniência no PSOL. (a"') De fato, ela não é negra, ela tem descendência indiana. ${ }^{21}$

(b"') É negra. O pai é jamaicano... negro. ${ }^{22}$

(c"') O PSOL defende as cotas, respeitando a mestiçagem e a descendência. ${ }^{23}$

Nessa terceira rede enunciativa, em (a"') Kamala Harris não é determinada como negra; há a negação de negra determinando Kamala Harris. O referencial histórico da descendência não considera a cor de Indiano como negra; A pertinência enunciativa é a

\footnotetext{
${ }^{21}$ Fragmento retirado do comentário de "EXTRA NEWS EXTRA" .

${ }^{22}$ Fragmento retirado do comentário de Neli Faria Faria.

${ }^{23}$ Enunciado de elaboração própria. 
negação da descendência Indiana para caracterizar negra; em (b"') a descendência Jamaicana do pai em o pai é negro determina a negritude de Kamala; a pertinência enunciativa é quem tem descendência Jamaicana é negra; Para analisarmos (c"') a cor de pele parda e mestiça e a descendência determinam Kamala Harris como negra; o referencial histórico tem a ver com mestiçagem e descendência, duas caracterizações respeitadas pelo PSOL. Ocorre que temos uma afirmação de Sérgio Camargo "No PSOL - negra por conveniência". Vamos especificar o referencial histórico da afirmação anterior. No PSOL, temos a inclusão do movimento negro no Brasil que instituiu as cotas, considerando mestiço, pardo e descendente de negro como “negro(a)". São as cotas que projetam Kamala Harris como negra. Como o locutor presidente (al-x) Sérgio Camargo não projeta negra nesse referencial histórico a pertinência enunciativa é de negra por conveniência, sustentada pelo referencial de interesse do partido.

\section{Considerações Finais}

Vamos tentar responder a pergunta inicial "Como negra é significada na convergência com o nome Kamala Harris dada a afirmação de dúvida de Sérgio Camargo? Como deslocar o conceito de performatividade?"

O Locutor Sérgio Camargo enuncia uma dúvida como um dizer genérico, incluindo outros nesse lugar de dúvida, desestabilizando um dizer universal que afirmava a negritude de Kamala. E o terceiro enunciado resposta integra-se a essa dúvida. Assim Sérgio Camargo desconstrói a certeza de que Kamala Harris é negra.

Como vimos, a resposta que é dada por ele, situa ser negra pela localização e pelo partido, assim, Kamala Harris só é chamada de negra nos EUA. A determinação do sentido de “negra(o)" se altera quando passa dos países para o partido político, o que se dá pela modificação do referencial histórico a que estes enunciados estão ancorados e, portanto, altera-se o que significa negra. Assim, nos dois primeiros enunciados a localização por país justificaria a diferença em designar Kamala pelo sentido de negra ou de mestiça/parda, sendo que no último enunciado temos uma mudança.

No último enunciado resposta, a determinação do sentido de negra por pôr conveniência traz o sentido de ser uma característica que se altera para ser favorecido, um oportunismo. Neste enunciado, vemos a divisão do Locutor: há um enunciador universal que diz que no PSOL, Kamala Harris é negra, mas há outro enunciador que considera que dizer que Kamala Harris é negra no PSOL é por conveniência, um dizer que é de um lugar 
individual, que estaria acima dos demais dizeres e fora da história, como se não fosse agenciado por lugares sociais.

O terceiro enunciado resposta integra-se à dúvida posta do lugar do dizer genérico. Ali o AL-x alude o Locutor e temos a dúvida inicial deslocada para uma crítica ao partido em questão. Em primeiro lugar a dúvida se dilui no enunciador genérico, isentando de certo modo a dúvida do Locutor. A nosso ver, tanto o dizer genérico como o dizer individual põem-se como cinismos, uma vez que apresentam uma crença diluída na dúvida e um deslize do AL-X aludindo o locutor. É desse modo que se dá o cinismo no recorte analisado. O Locutor enuncia como se aderisse à dúvida de outros, mas sua enunciação desliza para o lugar de origem do dizer e funciona de modo a desconsiderar os sentidos de negra do partido e, assim, produzir a sua crítica.

Do mesmo modo, a dúvida é demonstrada nas três redes enunciativas porque elas dão visibilidade à ancoragem das respostas no referencial histórico, a sua pertinência na relação de integração com a afirmação de dúvida.

O que se pode ver nas redes enunciativas são três concepções políticas de "negra(o)" na convergência com Kamala Harris a saber: a do povo americano, é negra por oposição à branco pelo referencial histórico da segregação, a do povo brasileiro, é mestiça ou parda pelo referencial histórico da mistura de raças, em que ser mestiço não é ser negro. E a do PSOL, pela relação de descendência e de mistura de raças, em que ser mestiça pela descendência é ser negra.

Estas três concepções estão presentes nas enunciações de resposta. No entanto, o locutor presidente da Fundação Cultural Palmares (al-x) alude ao Locutor Sérgio Camargo (L), produzindo um efeito de cinismo por não levar em consideração a concepção de negro do partido, ancorada no referencial histórico do movimento negro contra o racismo em defesa dos direitos dos negros pelo estabelecimento das cotas.

\section{Referências}

DIAS, Luiz Francisco. Enunciação e Relações Linguísticas. Campinas, SP: Pontes, 2018. . Redes enunciativas no ensino de Língua Portuguesa. In: Vertentes e Interfaces II:

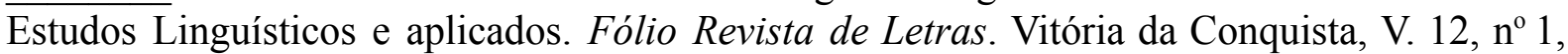
jan-jun. 2020.

FERNANDES, C. Tese do branqueamento. Disponível em: Tese do branqueamento. A tese do branqueamento no Brasil - Mundo Educação (uol.com.br) Acesso em: 20 fev. 2021. GUIMARÃES, E. Semântica do Acontecimento. Campinas, SP: Pontes, 2002.

. Semântica: Enunciação e sentido. Campinas, SP: Pontes Editores, 2018. 
HOFBAUER, A. Uma história de branqueamento ou o negro em questão. São Paulo: Editora UNESP, 2006.

LIMA, L. C. M. de; SZUBRIS, E. B.; RODRIGUES, M. L. M. Uma abordagem enunciativa das identificações de Descalvados. No prelo.

MACHADO, Carolina de Paula. O político e os sentidos: a produção das certezas na enunciação e seus efeitos em meio à pandemia. Anais do XXXV Encontro Nacional da Anpoll, 2020.

MAGNOLI, D. Uma gota de sangue: História do Pensamento Racial. São Paulo: Contexto, 2009.

PORFÍRIO, Francisco. Cotas Raciais. Disponível em: https://brasilescola.uol.com.br/educacao/sistema-cotas-racial.htm. Acesso em: 20 fev. 2021.

SILVA, Soeli Maria Schreiber da. Argumentação, Perspectivação e Enumeração no artigo 149 do código penal e em textos sobre o trabalho escravo. In.: Língua e Enunciação: Roteiros e Estações. Organizador: Luiz Francisco Dias. Belo Horizonte, FALE/UFMG, 2018 p. 360-373.

Recebido em: 15/01/2021; Aceito em: 18/03/2021. 